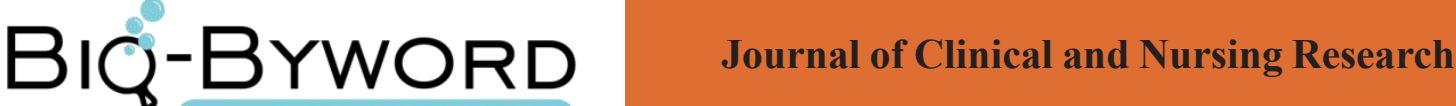

\section{Application of PDCA Circulatory Model in Digestive Endoscopic Nursing}

Qin Jian

Mianyang Third People's Hospital, Mianyang 621000, China

\section{ARTICLE INFO}

Article history:

Published online: $30^{\text {th }}$ Sept, 2017

\section{Key words:}

PDCA

Circulatory model

Digestive endoscopy

Nursing

Application

\begin{abstract}
Objective: To explore the application of PDCA circulatory model in hospital digestive endoscopic nursing and its application. Methods: 48 patients were randomly selected from the control group, and the patients were treated with a routine nursing operation. Eight patients with digestive endoscopy were selected as the observation group. On the basis of the implementation of general care and then increase the PDCA cycle model, and then the two groups of patients with a detailed comparison of care and research. Results: The nursing quality and satisfaction of the observation group were higher than those of the control group, and the contrast difference was significantly improved $(\mathrm{P}<0.05)$. Conclusion: The full application of PDCA circulatory model in digestive endoscopic nursing can effectively improve the quality of care for patients, and also improve the satisfaction of patients to a certain extent.
\end{abstract}

\section{Materials and methods}

\subsection{Information}

First, 48 patients with digestive endoscopy were selected as the control group. Then 48 patients with digestive endoscopy were randomly selected as the observation group. The observation group was added to the application of PDCA cycle model on the basis of general nursing. The control group included 27 male patients and 21 female patients aged between 21 to 75 years old. The mean age was $(48.26 \pm 5.14)$ years. The examination included 27 cases of gastroscopy, 11 cases two colonoscopy, 5 cases of enteroscopy, and 5 cases of colonoscopy. The observation group included 26 male patients and 22 female patients aged between 22 and 75 years old. The mean age was $(48.98 \pm 5.83)$ years. The examination included 25 cases of gastroscopy, 12 cases Duodenoscopy, 5 cases were treated with enteroscopy, and 6 cases were colonoscopy. There was no significant difference in sex, age, or type of microscopic examination between the two groups $(\mathrm{P}>0.05)$.

\subsection{Methods}

PDCA mode of application can be planned, processing, inspection and implementation of effective integration. The specific implementation process is as follows:

\subsubsection{Planning phase}

The design phase includes assessing care risks, analyzing related issues, and developing appropriate plans. In the assessment of nursing risks should be designed to manage a certain group, mainly should be the director of the department, nurse and nursing backbone, which is mainly responsible for the use of equipment, disinfection and isolation are goals and emergency management of emergency medicine; in the analysis of the problem is mainly the nursing process of the existence of some of the nursing risks in the full summary and analysis; To determine the corresponding planning links should be based on the analysis of the problems identified by the development of the corresponding treatment plans and measures to continuously improve the medical 
environment, but also the introduction of $5 \mathrm{~S}$ management philosophy, so that the operation of medical personnel more standardized.

Comparison of nursing quality between the two groups in digestive endoscopy

\begin{tabular}{|c|c|c|c|c|c|c|}
\hline Group & Case (n) & Basic care & Graed care & Ward care & Disinfection care & Skill operation \\
\hline Observation group & 48 & $\begin{array}{l}95.56 \\
\pm 4.32\end{array}$ & $\begin{array}{l}95.47 \\
\pm 3.75\end{array}$ & $\begin{array}{l}97.12 \\
\pm 3.83\end{array}$ & $95.17 \pm 4.26$ & $96.53 \pm 3.85$ \\
\hline Control group & 48 & $\begin{array}{l}81.23 \\
\pm 4.79\end{array}$ & $\begin{array}{l}80.45 \\
\pm 3.73\end{array}$ & $\begin{array}{l}81.58 \\
\pm 4.26\end{array}$ & $82.17 \pm 4.11$ & $80.39 \pm 3.92$ \\
\hline
\end{tabular}

\subsubsection{Implementation phase}

The implementation of the content mainly includes the management of the medical environment, such as drug zoning management, the effective classification of equipment storage and the diversion of medical personnel, etc. Continue to establish and improve the relevant safety management system, and constantly improve and clear the duties of various positions. The PDCA cycle model can be fully introduced into the division of labor work; in addition to the various infections should be effective prevention and control. For the control of the various details of the work should be clearly defined, including the duties of nurses and disinfection personnel responsibilities, etc., which can establish a certain system of reward and punishment to promote the smooth progress of work. In addition, the relevant care workers should also be some training and education work, and constantly enhance their digestive endoscopic nursing knowledge and technical level.

\section{Results}

A detailed comparison was made between the control group and the observation group. The results showed that the scores of nursing care in the observation group were higher than those in the control group, the data were significantly different $(\mathrm{P}<0.05)$. See the table below.

The satisfaction rate was $95.83 \%$ in the observation group and 39 cases in the control group. The satisfac- tion rate was $81.25 \%$ and the data were different $(\mathrm{P}<0.05)$. The satisfaction rate of the two groups was satisfactory, $\mathrm{P}<$ 0.05 .

\section{Discussion}

In the digestive system for the diagnosis and treatment of diseases, usually used to digest endoscopy, which can effectively ensure the smooth development of the entire diagnosis and treatment work and promote. But it also has its shortcomings, digestive endoscopy is very susceptible to bacterial contamination, it will give patients a certain risk if did not apply appropriate treatment, in this case, the introduction of PDCA cycle mode can be apply to ensure better safety of the entire process of use. According to the relevant research shows that PDCA cycle mode in the digestive endoscopic application of which can be a good all the planning, management and implementation process for effective integration of treatment and to achieve the patient's safety care and isolation and disinfection, but also the relevant instruments and positions to implement effective management, which can be seen in the PDCA cycle mode in the application of digestive endoscopy has a very obvious advantage. In the specific application process, the use of its advantages are mainly reflected in the following aspects: First, make the relevant medical staff care operation more standardized, such as the effective realization of the disinfection and isolation and basic care operations, so as to better ensure that the patient's safety care effect; Second, for the digestive endoscopic diagnosis and treatment work to provide a more effective protection, including the digestion of endoscopy and digestive endoscopy related to the use of instruments are more standardized, standardized operation also makes the operation more. But also the application of the model can also improve the overall quality of nursing staff because the PDCA model in the specific application process which pay more attention to the assessment mechanism and the assessment of the risk of the emergence of a variety of factors. The corresponding training work of continuous improvement and improvement, which can achieve the risk of digestive endoscopic care effective control.

\section{References}

[1] Niu Donghua, Zhang Haiyan, Zhao Juan. PDCA Cycle in Continuous Blood Purification Treatment of Patients with Pressure Ulcer Care Management Effect. Integrative Medicine, 2015, 2: 97-98.

[2] Liu Yimin, Jiang Jinju, Gong Yongmei. PDCA Circulatory System in Orthopedic Nursing Teaching Application. Modern diagnosis and treatment, 2015, 15: 3573-3574. 